\title{
Effect of Carbonization Conditions on the Property and Structure of Bamboo Char for Injection in Blast Furnace
}

\author{
Tengfei SONG, ${ }^{1)}$ Jianliang ZHANG, ${ }^{1)}$ Guangwei WANG, ${ }^{1) *}$ Haiyang WANG, ${ }^{1)}$ Runsheng $X U^{, 2)}$ Qinghai PANG ${ }^{3)}$ \\ and Chuan WANG ${ }^{4,5)}$ \\ 1) School of Metallurgical and Ecological Engineering, University of Science and Technology Beijing, Beijing, 100083 China. \\ 2) State key laboratory of refractories and metallurgy, Wuhan University of Science and Technology, Wuhan, 430081 China. \\ 3) School of Materials and Metallurgy, University of Science and Technology Liaoning, Anshan, 114051 China. \\ 4) Swerea MEFOS, SE-971 25 Luleå, Sweden. \\ 5) Thermal and Flow Engineering Laboratory, Åbo Akademi University, Åbo, Fl-20500 Finland.
}

(Received on June 26, 2018; accepted on October 23, 2018; J-STAGE Advance published date: December 15, 2018)

\begin{abstract}
To evaluate the effect of carbonization conditions on the bamboo, the relationship between carbonization parameter and physicochemical characteristics was studied. The results indicated that the volatile matter drastically decreased with the increase of carbonization temperature, while the fixed carbon and fuel ratio (fixed carbon/volatile matter) increased. Excellent linearity between the fuel ratio and carbonization temperature was obtained. The energy yield decreased gradually when rising the carbonization temperature, whereas the change of heating value was not obvious. A new calculation model of higher heating value (HHV) was developed, and it could be used to predict HHV of the bamboo char more precisely at temperatures above $300^{\circ} \mathrm{C}$. The positive impact of functional groups, specific surface area as well as catalysis of alkali metal may contribute to the combustion of bamboo char. The results showed that there is a feasible operating condition for the transformation of bamboo into char with the carbonization parameter at $400^{\circ} \mathrm{C}$ for $30 \mathrm{~min}$.
\end{abstract}

KEY WORDS: bamboo; blast furnace injection; carbonization conditions; heating value; combustion.

\section{Introduction}

With the development of steel industry, a large amount of the greenhouse gas emission and the energy consumption have been paid more and more attention in the process of blast furnace (BF) ironmaking. ${ }^{1)}$ The coking coal used to produce coke has become very limited in the world. To some extent, the injection of pulverized coal though the tuyere can reduce the coke consumption., ${ }^{2,3)}$ Even though the life of the scarce coking coal reserves may be prolonged, the injection material, especially bitumite coal and anthracite coal, cannot be expected to survive indefinitely. ${ }^{4)}$

Bamboo, a promising feedstock with high growth rate, wide distribution and easy propagation in China, is viewed as a replacement of fossil fuel. ${ }^{5,6)}$ However, due to its high oxygen content, low calorific value, and high moisture content as well as low grindability, ${ }^{7-9)}$ its application is limited. In recent years, to overcome these drawback, many effective conversion methods have been developed, such as thermal treatment, microwave heating, palletization. ${ }^{10-12)}$ Among them, thermal treatment, including torrefaction and carbonization, is considered as one of most efficient ways to upgrade the properties of biomass material. ${ }^{13,14)}$ Three dif-

\footnotetext{
* Corresponding author: E-mail: wgw676@163.com

DOI: https://doi.org/10.2355/isijinternational.ISIJINT-2018-460
}

ferent torrefaction temperatures were introduced by Rousset et al. ${ }^{15)}$ at temperature of 220,250 and $280^{\circ} \mathrm{C}$. It was found that the elementary composition of torrefied bamboo tend toward those of lignite and coal attributed to carbonyl groups and aromatic groups. Chen et al. investigated the torrefied bamboo obtained from torrefaction at 250 and $300^{\circ} \mathrm{C}$ for $1 \mathrm{~h}$ duration for the blast furnace injection. ${ }^{16)}$ They found that the torrefied bamboo can be used as alternative fuels to high-volatile bituminous coals and torrefaction at $300^{\circ} \mathrm{C}$ was a feasible operating condition to transform bamboo into torrefied bamboo for $\mathrm{BF}$ injection. Thus, torrefaction has a lot of merits in upgrading the properties of bamboo. ${ }^{17,18)}$

Nowadays, many attentions have been paid to bamboo torrefaction at the temperature of less than $300^{\circ} \mathrm{C} .{ }^{15,19)}$ However, the volatile matter content of the solid product (referred to as bamboo char) subjected to torrefaction was high, for some cases it was even more than $50 \%$. As a result, the torrefied bamboo is generally blended with the anthracite coal which has ignition temperature, and burnout temperature..$^{20,21)}$ To the authors' knowledge, few researches in the thermal treatment temperature over $400^{\circ} \mathrm{C}$ or even higher for bamboo has been studied. Thus, the aim of the present study was to investigate the basic properties of bamboo pretreated by carbonization in the temperature range of $400^{\circ} \mathrm{C}-700^{\circ} \mathrm{C}$, by comparing with bitumite coal and anthracite coal. The results from this work will be use- 
ful in understanding the feasibility of the bamboo char for injection in the BF.

\section{Experimental Materials and Methods}

\subsection{Materials}

The bamboo chosen was one type of construction waste from one building site located in Beijing, China. The bamboo (labelled as B) was sawn into approximately $5 \mathrm{~cm}$ pieces in length to ensure the homogeneous treatment in the process of carbonization. As a contrast, a high volatile matter coal (labelled as DL) and a low volatile matter coal (labelled as HY) for injection in the blast furnace were chosen. The proximate analyses, ultimate analyses as well as the composition of ash are listed in Tables $\mathbf{1}$ and $\mathbf{2}$.

\subsection{Carbonization Method}

The preliminary study of the bamboo carbonization process was investigated by using the HCT-3 thermal balance to determine the appropriate carbonization temperature for further experiments (signal to noise ratio: 10:1). $5 \mathrm{mg} \pm 0.1$ $\mathrm{mg}$ of bamboo crumbs (length of $0.6 \mathrm{~mm}$ to $0.8 \mathrm{~mm}$ ) was heated from the ambient temperature to $1000^{\circ} \mathrm{C}$ at the rate $10^{\circ} \mathrm{C} / \mathrm{min}$ in argon $(60 \mathrm{~mL} / \mathrm{min})$ atmosphere. The sample was held for $30 \mathrm{~min}$ every $100^{\circ} \mathrm{C}$ from $300^{\circ} \mathrm{C}$ to $1000^{\circ} \mathrm{C}$.

Based on the results from the thermal balance experiment, the bamboo char was manufactured using a tube furnace. The carbonization process was performed in an argon atmosphere $(5 \mathrm{~L} / \mathrm{min})$ with different carbonization temperatures $\left(400^{\circ} \mathrm{C}, 500^{\circ} \mathrm{C}, 600^{\circ} \mathrm{C}\right.$, and $\left.700^{\circ} \mathrm{C}\right)$ and duration time (30 $\mathrm{min}$ and $60 \mathrm{~min}$ ). After carbonization, the reactor was cooled to ambient temperature in an argon atmosphere. The bamboo char was crushed and sieved to be less than $74 \mu \mathrm{m}$. The bamboo char samples were labeled with different identification numbers. For instance, B-400-30 meant that the bamboo char samples were obtained at $400^{\circ} \mathrm{C}$ for $30 \mathrm{~min}$.

\subsection{Basic Characteristic Measurement}

The HHV and proximate/ultimate analysis were determined according to the Chinese National Standards (GB/T 213; GB/T 212; GB/T 476). The experiments of samples were repeated three times and took the average. Meanwhile, the X-ray fluorescence (XRF-18000, Shimadzu Corporation, Tokyo, Japan) was performed for the ash composition. The microstructure of samples was observed by using Scanning electron microscopy (SEM) (FEI Quanta-450).

The combustion characteristic of samples was studied by the HCT-3 thermal balance. Approximately $5 \mathrm{mg} \pm 0.1$ $\mathrm{mg}$ of samples was heated from the ambient temperature to $900^{\circ} \mathrm{C}$ at the heating rate of $15^{\circ} \mathrm{C} / \mathrm{min}$. The flow rate of the air introduced into the thermal balance during the combustion experiments was $60 \mathrm{~mL} / \mathrm{min}$. To evaluate the combustion characteristics, the comprehensive combustion characteristic index $\mathrm{S}$ was defined as, ${ }^{22}$

$$
\mathrm{S}=\frac{(\mathrm{dx} / \mathrm{dt})_{\max } \cdot(\mathrm{dx} / \mathrm{dt})_{\text {mean }}}{T_{i}^{2} \cdot T_{f}}
$$

where $(\mathrm{dx} / \mathrm{dt})_{\max }$ is the maximum conversion rate $(\mathrm{mg} / \mathrm{min})$, $(\mathrm{dx} / \mathrm{dt})_{\text {mean }}$ represents the mean value of the conversion rate (mg/min), $T_{i}$ is the initial temperature $\left({ }^{\circ} \mathrm{C}\right)$, and $T_{f}$ is the burnout temperature $\left.\left({ }^{\circ} \mathrm{C}\right) .{ }^{23}\right)$

\subsection{Determination of FTIR Parameters}

The Fourier transform infrared (FTIR) investigation of samples was performed by using a Nicolet iS5 FTIR spectrometer (Spectral range: $8000-350 \mathrm{~cm}^{-1}$, signal to noise ratio: $40000: 1$ ) with the scan region of $4000 \mathrm{~cm}^{-1}$ to 400 $\mathrm{cm}^{-1}$. The FTIR spectra were recorded by scanning 16 times at a resolution of $4.0 \mathrm{~cm}-1$ using potassium bromide/coal pellet technique in the ratio of 100:1.

According to the widely used technique, ${ }^{24,25)}$ the concentration of aliphatic $\left(H_{a l}\right)$ and aromatic $\left(H_{a r}\right)$ hydrogen was determined using the absorbances from spectral zones $\left(3000-2800 \mathrm{~cm}^{-1}\right.$ and $900-700 \mathrm{~cm}^{-1}$ ).

$$
\mathrm{S}=\frac{(\mathrm{dx} / \mathrm{dt})_{\max } \cdot(\mathrm{dx} / \mathrm{dt})_{\text {mean }}}{T_{i}^{2} \cdot T_{f}}
$$

$$
H_{a r}=\frac{A_{a r}}{a_{a r}}=\frac{A_{900-730 \mathrm{~cm}^{-1}}}{a_{a r}}
$$

where $A_{3000-2800 \mathrm{~cm}^{-1}}$ and $A_{900-730 \mathrm{~cm}^{-1}}$ are the integrated areas

\begin{tabular}{|c|c|c|c|c|c|c|c|c|c|c|c|}
\hline \multirow{2}{*}{ Sample } & \multicolumn{5}{|c|}{ Proximate Analysis (wt.\%) } & \multicolumn{5}{|c|}{ Ultimate Analysis (wt.\%) } & \multirow{3}{*}{$\begin{array}{c}\mathrm{HHV}(\mathrm{kJ} / \mathrm{g}) \\
19.50\end{array}$} \\
\hline & Mad & Aad & $\mathrm{Vad}$ & FCad & $\mathrm{FC} / \mathrm{V}$ & $\mathrm{C}$ & $\mathrm{H}$ & $\mathrm{O}^{*}$ & $\mathrm{~N}$ & $\mathrm{~S}$ & \\
\hline B & 4.22 & 1.81 & 74.53 & 19.44 & 0.26 & 48.06 & 5.34 & 46.16 & 0.40 & 0.04 & \\
\hline Coal DL & 4.95 & 10.41 & 23.40 & 61.24 & 2.62 & 83.19 & 4.60 & 11.01 & 0.92 & 0.28 & 26.7 \\
\hline Coal HY & 8.31 & 12.93 & 8.14 & 78.93 & 9.70 & 91.27 & 3.89 & 2.03 & 2.10 & 0.71 & 29.9 \\
\hline
\end{tabular}
of aliphatic and aromatic $\mathrm{C}-\mathrm{H}$ stretching regions, as deter-

Table 1. Proximate and ultimate analysis of samples.

Note: M: moisture; A: ash; V: volatile matter; FC: fixed carbon, ad: air dried basis; *: by difference, HHV: higher heating value; FC/V: fuel ratio (defined as the ratio of the fixed carbon to the volatile matter.

Table 2. Composition of ash obtained from different samples by XRF analyses, $\%$.

\begin{tabular}{rcccccccccc}
\hline Sample & Ash Content & \multicolumn{1}{c}{$\mathrm{K}_{2} \mathrm{O}$} & $\mathrm{Na}_{2} \mathrm{O}$ & $\mathrm{CaO}$ & $\mathrm{SiO}_{2}$ & $\mathrm{MgO}$ & $\mathrm{P}_{2} \mathrm{O}_{5}$ & $\mathrm{Fe}_{2} \mathrm{O}_{3}$ & $\mathrm{Al}_{2} \mathrm{O}_{3}$ & $\mathrm{Cl}$ \\
\hline Coal DL & 10.41 & 1.80 & 0.76 & 13.99 & 46.73 & 2.00 & 0.41 & 10.13 & 19.10 & $<0.02$ \\
Coal HY & 12.93 & 0.45 & 3.51 & 23.82 & 26.84 & 5.34 & 0.23 & 11.61 & 15.15 & $<0.02$ \\
Bamboo & 1.81 & 61.59 & 0.16 & 4.04 & 9.49 & 2.64 & 12.35 & 2.52 & 1.10 & 0.93 \\
\hline
\end{tabular}


mined from the bonds at $3000-2800 \mathrm{~cm}^{-1}$ and 900-700 $\mathrm{cm}^{-1}$, respectively; the integral absorptivities of $a_{a l}$ and $a_{a r}$ are related to the areas to the hydrogen concentrations $\left(a_{a l}=746\right.$ and $a_{a r}=686$ absorbance units $\mathrm{cm}^{-1} \mathrm{mg}^{-1} \mathrm{~cm}^{2}$ for coals and chars).

The apparent aromaticity, $f_{\mathrm{a} \text { (FTIR) }}$, of samples was used to characterize the aromatic carbon fraction, and it was estimated using the following equation:

$$
\begin{gathered}
\frac{H_{a l}}{H}=\frac{H_{a l}}{H_{a l}+H_{a r}} \cdots . . . \\
\frac{C_{a l}}{C}=\left(\frac{H_{a l}}{H} \times \frac{H}{C}\right) / \frac{H_{a l}}{C_{a l}} \\
f_{\mathrm{a} \text { (FTIR) }}=1-\frac{C_{a l}}{C} \cdots . . .
\end{gathered}
$$

Where $H_{a l} / H$ represents the fraction of the concentrations of aliphatic $\left(H_{a l}\right)$ and the total hydrogen atoms $(\mathrm{H})$, obtained from the FTIR data; $C_{a l} / C$ is the aliphatic structure fraction; $H / C$ is the ratio of hydrogen atoms to carbon atoms, calculated from the ultimate analysis; $H_{a l} / C_{a l}$ is the ratio of hydrogen atoms and carbon atoms in aliphatic groups, approximate 1.8 for coals.

\section{Results and Discussion}

\subsection{Carbonization Process}

As presented in Fig. 1, the carbonization process could be divided into three stages: in the first stage, from ambient temperature to the beginning of $300^{\circ} \mathrm{C}$, mass loss quickly occurred and the conversion rate reached the maximum. The second stage was from the beginning of $300^{\circ} \mathrm{C}$ to the end of $500^{\circ} \mathrm{C}$. The mass loss showed a step down in this stage. Moreover, the curve of mass loss had an obvious turning point between the heating zone and holding zone, indicating that the carbonization process is mainly affected by the temperature. The third stage was from $500^{\circ} \mathrm{C}$ to $1000^{\circ} \mathrm{C}$. In this stage, the curve of mass loss was essentially flat, meaning that the carbonization process is almost completed.

It is well known that bamboo is a kind of herb containing more hemicellulose than cellulose and the reactivity of hemicellulose is higher than that of the cellulose and lignin. ${ }^{15,26)}$ The mass loss rate was up to $69 \%$ at the end of $300^{\circ} \mathrm{C}$. It meant that the hemicellulose decomposition first occurred, and the other two components were partly

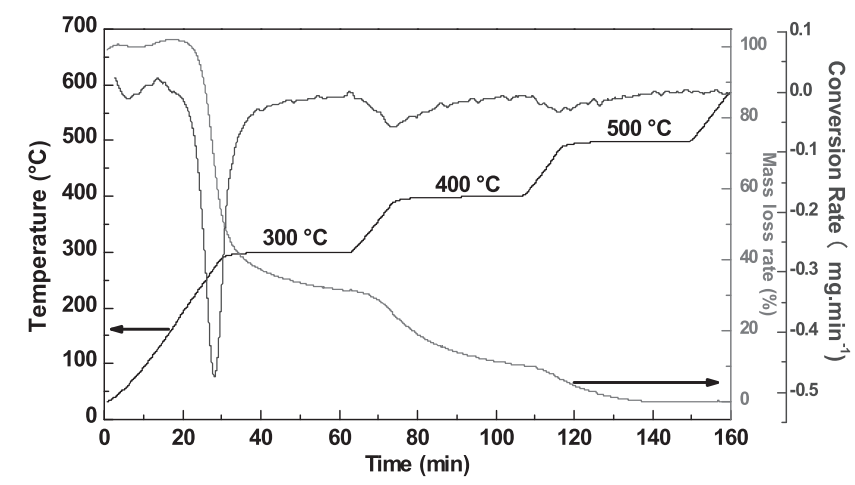

Fig. 1. Carbonization process of bamboo. decomposed as well. ${ }^{27,28)}$ As the temperature increased, the cellulose and lignin started to decompose, until the sample was completely decomposed. In the bamboo pyrolysis process, a few small molecule gases (e.g. $\mathrm{CO}_{2}, \mathrm{CO}$ and $\mathrm{CH}_{4}$ ) were released attributed to the cleavage of functional groups. According to the report about bamboo pyrolysis Liang et al. ${ }^{29)} 70 \%$ of weight loss for bamboo occurred at the temperature of $200-400^{\circ} \mathrm{C}$. the $\mathrm{CO}_{2}$ was the main gas component for bamboo pyrolysis products, which the main released temperature range is $150-350^{\circ} \mathrm{C}$. Though the $\mathrm{CO}$ and $\mathrm{CH}_{4}$ content was far less than $\mathrm{CO}_{2}$, the $\mathrm{CO}$ and $\mathrm{CH}_{4}$ release had a similar trend with the $\mathrm{CO}_{2}$.

\subsection{Proximate Analysis}

The proximate analysis and solid yield $\left(\eta=\mathrm{m}_{1} / \mathrm{m}_{2} * 100\right.$, $\mathrm{m}_{1}, \mathrm{~m}_{2}$ : the mass of bamboo char and bamboo, respectively) of bamboo char and coal are listed in Table 3. As shown in Fig. 2(a), comparing with the solid yield of the bamboo char suffered from $30 \mathrm{~min}$ and $60 \mathrm{~min}$ duration, the solid yield was minimally affected by the duration time, and this was in agreement with a previous study. ${ }^{30)}$ Thus, considering the aspects of economy and the production efficiency, carbonization for less than $30 \mathrm{~min}$ duration is a feasible operating condition to transform the bamboo into char for the injection.

The ash content of bamboo before and after carbonization for $30 \mathrm{~min}$ duration was approximately $1.81 \%$ to $4.62 \%$, which was far less than that of coals and was close to bamboo char obtained from carbonization temperature of $1000^{\circ} \mathrm{C}$ for $30 \mathrm{~min}$ duration ${ }^{31)}$ The content of volatile matter had a contrary trend with that of fixed carbon with the carbonization temperature rising, as shown in Figs. 2(b) and 2(c). Thus, the fuel ratio (FC/V) of bamboo char presented a tendency to linearly increase with the carbonization temperature rising, which lay between coal HY and coal DL, as displayed in Fig. 2(d). From the viewpoint of the proximate analysis, the bamboo char obtained at carbonization temperatures in the range from $400^{\circ} \mathrm{C}$ to $700^{\circ} \mathrm{C}$ had a great potential as an alternative injection fuel for the blast furnace.

Volatile matter releases more heat than fixed carbon, which has a negative correlation with the ash content. ${ }^{15,32,33)}$ Although the fuel ratio of bamboo char obtained at $700^{\circ} \mathrm{C}$ was 8.62, less than coal HY (9.69), the heat of bamboo char was much higher due to obvious advantages of the higher fixed carbon and the lower ash content compared to coal

Table 3. Proximate analysis and solid yield of bamboo char.

\begin{tabular}{cccccc}
\hline Sample & Aad (\%) & Vad (\%) & FCad (\%) & $\begin{array}{c}\text { Fuel Ratio } \\
(\mathrm{FC} / \mathrm{V})\end{array}$ & $\begin{array}{c}\text { Solid Yield } \\
(\eta, \%)\end{array}$ \\
\hline B-400-30 & 3.16 & 29.22 & 67.62 & 2.31 & 35.53 \\
B-500-30 & 4.45 & 16.21 & 79.34 & 4.89 & 26.29 \\
B-600-30 & 4.59 & 12.45 & 82.96 & 6.66 & 24.3 \\
B-700-30 & 4.62 & 9.91 & 85.47 & 8.62 & 22.18 \\
B-400-60 & 3.41 & 28.41 & 68.18 & 2.40 & 34.72 \\
B-500-60 & 4.47 & 16.12 & 79.41 & 4.93 & 26.17 \\
B-600-60 & 4.51 & 11.11 & 84.38 & 7.59 & 23.54 \\
B-700-60 & 4.71 & 9.90 & 85.39 & 8.63 & 21.33 \\
\hline
\end{tabular}




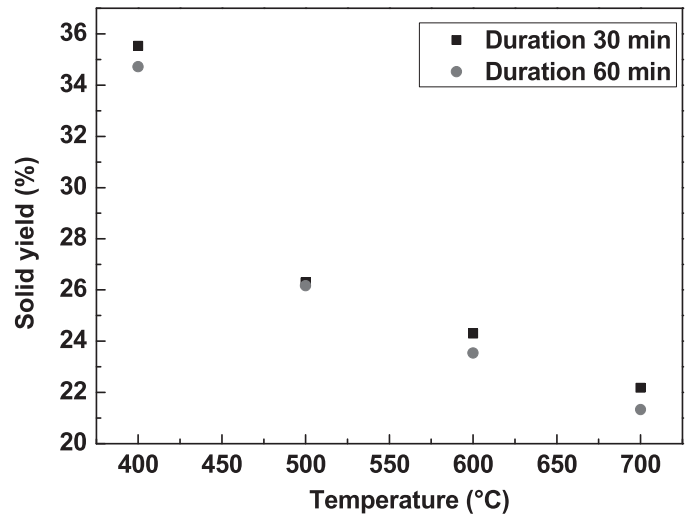

(a)

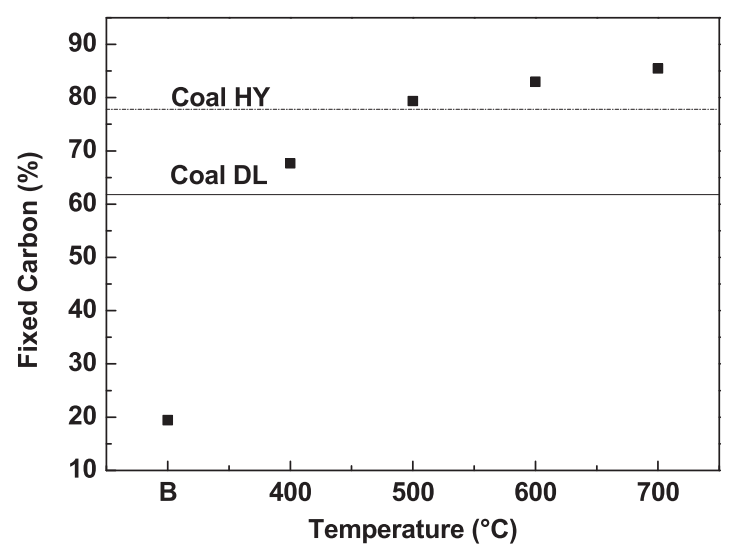

(c)

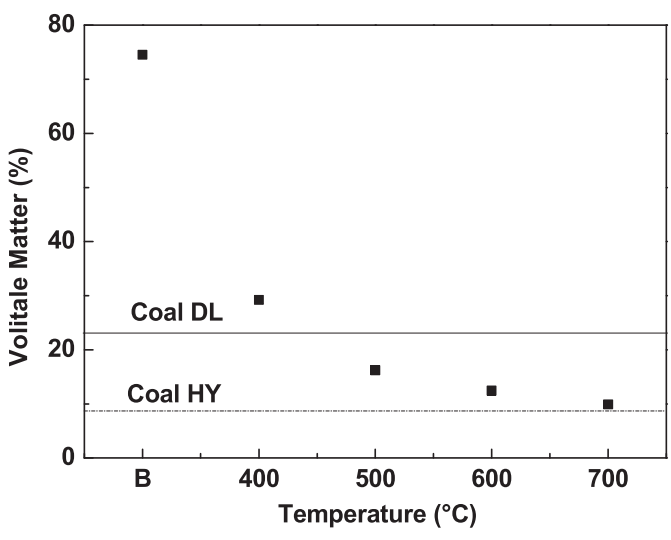

(b)

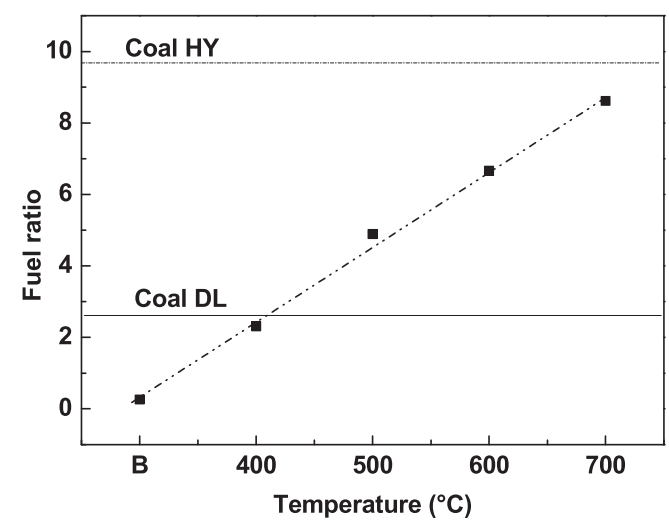

(d)

Fig. 2. (a) Solid yield, (b) volatile matter, (c) fixed carbon, and (d) fuel ratio of sample.

HY. Accordingly, from the viewpoint of coal replacement, the feasible carbonization temperature should be conducted at above $400^{\circ} \mathrm{C}$.

\subsection{Energy Characteristics of Bamboo Char}

The HHV and solid yield are important parameters in determining the effect of carbonization conditions on the bamboo property. The organic part of the bamboo was removed in the form of gas and liquid during carbonization. The treatment, carbonization at $400^{\circ} \mathrm{C}$ for $30 \mathrm{~min}$, had a substantial effect on the HHV of bamboo char with a considerable increase from $19.2 \mathrm{~kJ} / \mathrm{g}$ to $26.6 \mathrm{~kJ} / \mathrm{g}$ in comparison with the bamboo, about $38.5 \%$ increase as listed in Table 4. Nevertheless, the increase rate of HHV, from $53.6 \%$ to $59.9 \%$, had flat-lined with the rise of carbonization temperature sequentially. Therefore, the heat of fixed carbon is approximately equal to that of volatile matter for bamboo char obtained at the temperature of above $500^{\circ} \mathrm{C}$.

$\mathrm{HHV}$ is mainly affected by the chemical component. The oxygen and hydrogen decreased with the increase of temperature, while the nitrogen content remained almost constant, as listed in Table 4. $\mathrm{Liu}^{34)}$ calculated the HHV of bamboo char carbonized at temperatures below $300^{\circ} \mathrm{C}$ using Dulong's formula ${ }^{35)}$ as a function of the $\mathrm{C}, \mathrm{H}, \mathrm{O}$, and $\mathrm{N}$ contents. The error of calculation value and experiment value was very small. The formula could be expressed as:

$$
\begin{aligned}
& \mathrm{HHV}_{\text {cal }}= \\
& (33.5 \times \mathrm{C}+142.3 \times \mathrm{H}-15.4 \times \mathrm{O}-14.5 \times \mathrm{N}) \times 10^{-2}
\end{aligned}
$$

The Dulong's formula is usually only used to calculate the HHV of char obtained at the temperature of below $300^{\circ} \mathrm{C}$. However, using the formula (7), a good liner relationship between the calculated value and experimental value still existed, as shown in Fig. 3(a), and the $\mathrm{R}^{2}$ was 0.978. Meanwhile, by SPSS (data statistical analysis software), we got the following expression:

$$
\begin{aligned}
& \mathrm{HHV}_{\text {new }}= \\
& (33.85 \times \mathrm{C}+1.252 \times \mathrm{H}+6.25 \times \mathrm{O}+70.92 \times \mathrm{N}) \times 10^{-2}
\end{aligned}
$$

The degree of fitting $\left(\mathrm{R}_{2}=0.999\right)$ of the modified formula was better than that of Dulong's formula, indicating that the formula (8) is more appropriate to be applied to estimate the $\mathrm{HHV}$ of bamboo char obtained at temperatures above $300^{\circ} \mathrm{C}$.

In addition, the solid yield could not be ignored. Because the aim of carbonization was to improve the property of bamboo for further utilization in the blast furnace, the energy balance should be considered. Hence, the energy yield formula was developed to consider the combined effect of the HHV and solid yield, ${ }^{36)}$

$$
\eta_{e}=\eta \times\left(G_{2} / G_{1}\right)
$$

where $\eta_{e}$ is the energy yield (\%), $\eta$ is the solid yield (\%), and $G_{1}$ and $G_{2}$ are the HHV of bamboo and bamboo char $(\mathrm{kJ} / \mathrm{g})$, respectively. The energy yield became lower with the rising temperature, which decreased from $49.2 \%$ to $35.4 \%$, i.e., only $35.4 \%$ of energy content was retained in the bam- 
Table 4. HHV, energy yield, and ultimate analysis of bamboo chars.

\begin{tabular}{ccccccccc}
\hline Sample & $\mathrm{C}(\%)$ & $\mathrm{H}(\%)$ & $\mathrm{O}(\%)$ & $\mathrm{N}(\%)$ & $\mathrm{HHV}(\mathrm{kJ} / \mathrm{g})$ & $\mathrm{HHV}$ cal $(\mathrm{kJ} / \mathrm{g})$ & Increase Rate of HHV $(\%)$ & Energy Yield (\%) \\
\hline B-400-30 & $73.12 \pm 0.12$ & $3.63 \pm 0.09$ & $22.78 \pm 0.05$ & $0.47 \pm 0.02$ & $26.6 \pm 0.06$ & 26.1 & 38.5 & 49.2 \\
B-500-30 & $83.68 \pm 0.09$ & $2.49 \pm 0.10$ & $13.32 \pm 0.05$ & $0.51 \pm 0.02$ & $29.5 \pm 0.05$ & 29.5 & 53.6 & 40.3 \\
B-600-30 & $84.12 \pm 0.01$ & $2.45 \pm 0.07$ & $12.80 \pm 0.02$ & $0.63 \pm 0.01$ & $29.7 \pm 0.08$ & 29.6 & 54.7 & 37.4 \\
B-700-30 & $87.23 \pm 0.10$ & $1.88 \pm 0.02$ & $10.24 \pm 0.10$ & $0.65 \pm 0.05$ & $30.7 \pm 0.01$ & 30.2 & 59.9 & 35.4 \\
\hline
\end{tabular}

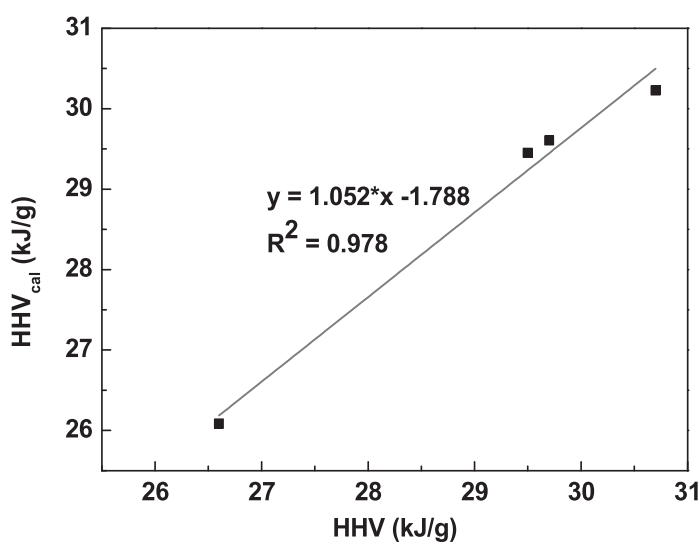

(a)

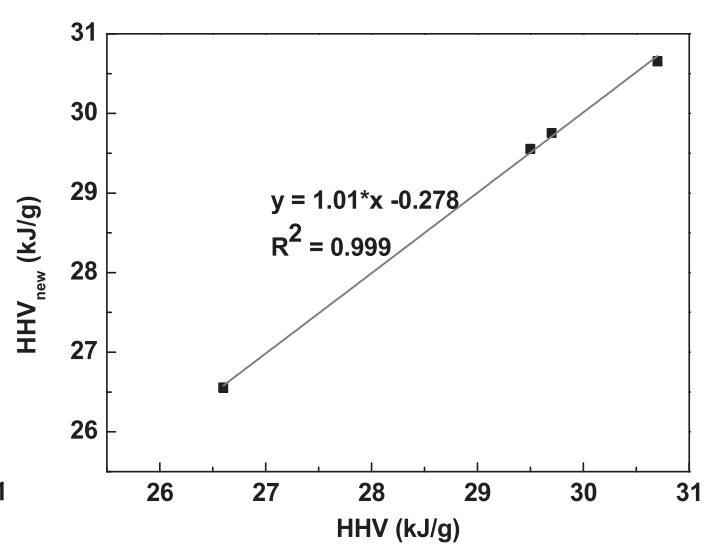

(b)

Fig. 3. Relationship of the calculated $\mathrm{HHV}_{\text {cal }} / \mathrm{HHV}_{\text {new }}$ and the experimental $\mathrm{HHV}$.

boo char after $700^{\circ} \mathrm{C}$ carbonization. The effect of carbonization temperature on the solid yield is obviously greater than the HHV. There was a linear correlation between the energy yield and solid yield as shown in Fig. 4. The $\mathrm{R}^{2}$ value was 0.997 , suggesting that the solid yield could be used to predict the energy yield for bamboo char obtained at temperatures above $300^{\circ} \mathrm{C}$ as well. ${ }^{37,38)}$

\subsection{Combustion Analysis}

The conversion and conversion rate of samples are shown in Fig. 5. As shown in the figure, the combustion curve of bamboo char moved to a higher temperature zone when rising temperature, which proved that the higher carbonization temperature worsened the combustibility of bamboo char. Moreover, the combustion curve of bamboo chars located at the left of those of coals, indicating that bamboo char could start to burn earlier, and it had a lower burnout temperature.

The combustion characteristics parameters and specific surface area of samples are listed in Table 5. The initial temperature of bamboo char increased from $342.8^{\circ} \mathrm{C}$ to $383.0^{\circ} \mathrm{C}$, and the burnout temperature was from $440.0^{\circ} \mathrm{C}$ to $490.2^{\circ} \mathrm{C}$ with the rising carbonization temperature, which were both respectively lower than those of the coals. Consequently, the bamboo char would burn completely and release tremendous amounts of energy in a shorter period, which was of importance to suppress the negative effect of unburned coal powder on permeability in the blast furnace. The porous structure of bamboo char would provide good conditions for introducing reactant gas into the inside of particles and probably accelerate the interface reactions as shown in Fig. 6. In contrast, because of the smooth surface of coals, the combustion reaction only occurred on the external surface of coal particles. However, the specific surface of samples could not be analyzed quantitatively according

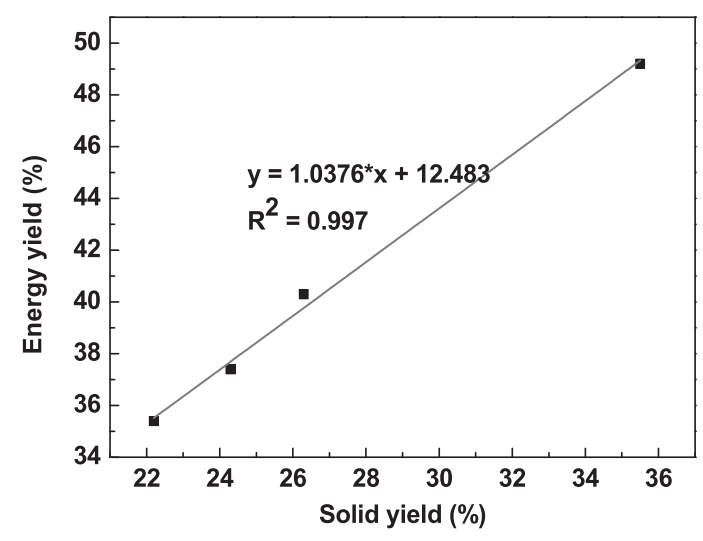

Fig. 4. Relationship of energy yield and solid yield.

to the SEM images. The $\mathrm{N}_{2}$ adsorption $(77 \mathrm{~K})$ technique was used to determine the porous structure of samples and specific surface area quantitatively. As listed in Table 5, the specific surface area of bamboo char was larger than 247 $\mathrm{m}^{2} / \mathrm{g}$. The influence of the specific surface area of bamboo char on the improving the combustion reaction can never be neglected.

The comprehensive combustion characteristic index $\mathrm{S}$ for samples was shown in Fig. 7. With the increase of carbonization temperature, though the index $\mathrm{S}$ for bamboo char gradually decreased from 11.17 to 6.73 , the bamboo char still showed a higher combustion performance compared with coals. The order of index $\mathrm{S}$ of samples were ranked as: B-400-30 > B-500-30 > B-600-30 > B-700-30 > Coal DL > Coal HY. Obviously, we could see that the index $S$ had a good consistency with the combustion characteristic. If the bamboo char was used for injection, the combustibility of bamboo chars was absolutely not the restrictive factor. 


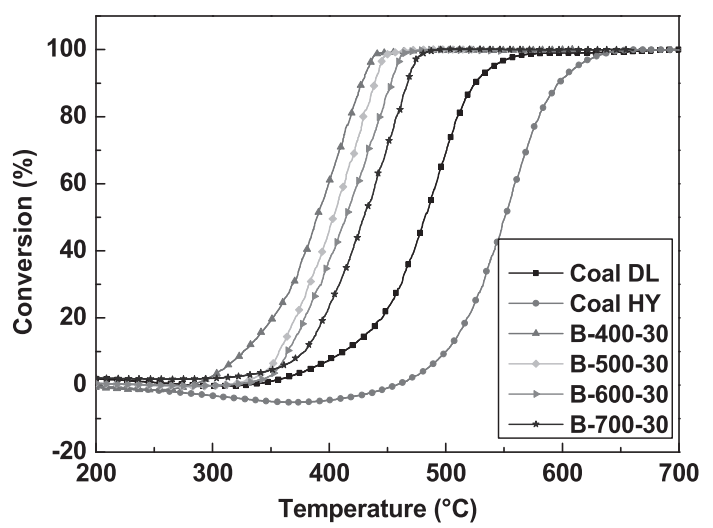

(a)

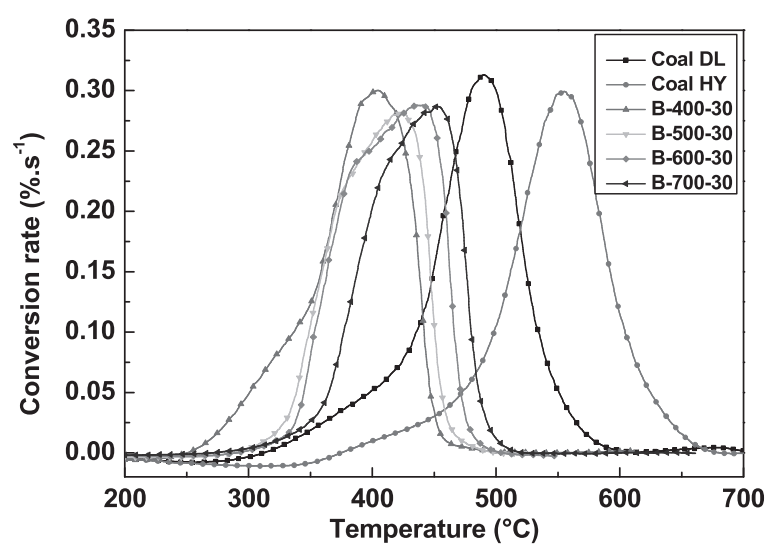

(b)

Fig. 5. Combustion curve of bamboo char, coal DL, and coal HY: a: conversion, b: conversion rate.

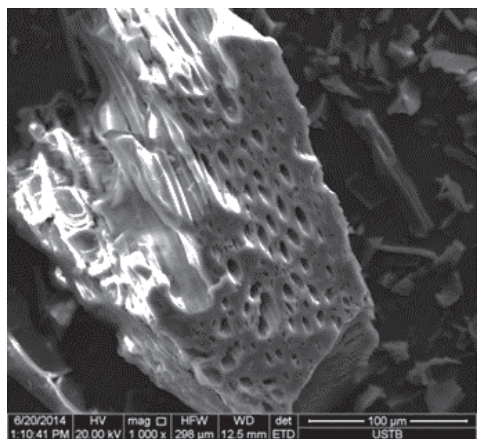

(a)

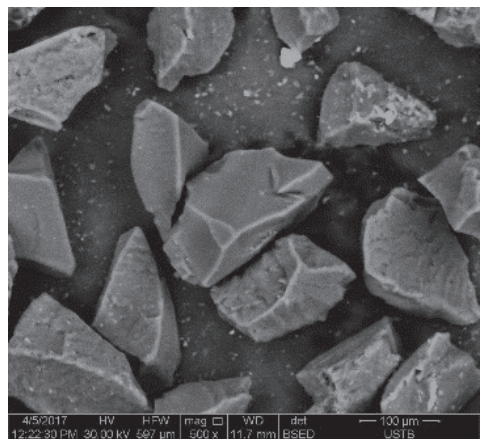

(b)

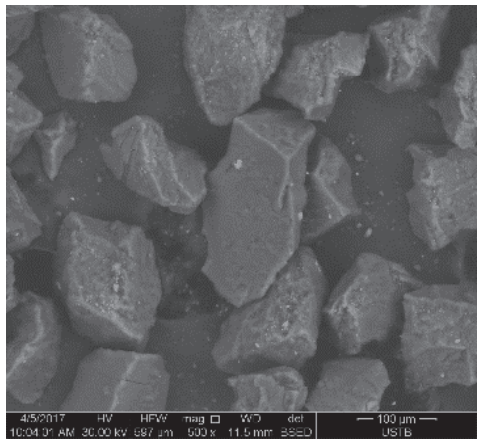

(c)

Fig. 6. SEM images of bamboo char and coals, a: coal DL; b: coal HY; c: bamboo char.

Table 5. Combustion characteristics parameters and specific surface area of bamboo char and coals.

\begin{tabular}{cccccc}
\hline Sample & $T_{\mathrm{i}}\left({ }^{\circ} \mathrm{C}\right)$ & $\begin{array}{c}(d x / d t)_{\max }, \\
\mathrm{mg} / \mathrm{min}\end{array}$ & $\begin{array}{c}(d x / d t)_{\text {mean }} \\
\mathrm{mg} / \mathrm{min}\end{array}$ & $T_{\mathrm{f}}\left({ }^{\circ} \mathrm{C}\right)$ & $\begin{array}{c}\text { specific surface } \\
\text { area }, \mathrm{m}^{2} / \mathrm{g}\end{array}$ \\
\hline Coal DL & 433.8 & 0.84 & 0.52 & 558.0 & 3.6 \\
Coal HY & 504.4 & 0.78 & 0.49 & 630.0 & 2.2 \\
B-400-30 & 342.8 & 0.87 & 0.66 & 440.0 & 247.3 \\
B-500-30 & 358.0 & 0.80 & 0.61 & 455.3 & 267.7 \\
B-600-30 & 373.8 & 0.80 & 0.62 & 480.5 & 279.9 \\
B-700-30 & 383.0 & 0.82 & 0.59 & 490.2 & 281.2 \\
\hline
\end{tabular}

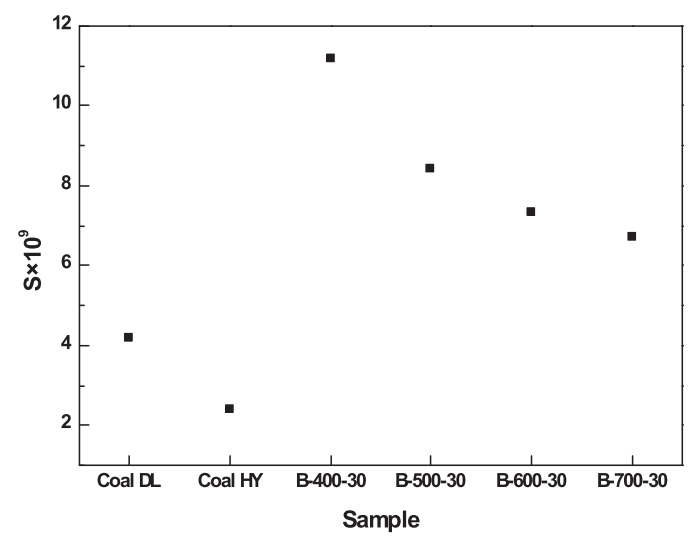

Fig. 7. Comprehensive gasification characteristic index S of samples.

\subsection{Ash Composition and Functional Group}

Bamboo contained plenty of potassium oxide, up to $61.59 \%$, as listed in Table 2. It is well known that alkali metal in the ash, such as $\mathrm{K}$ and $\mathrm{Na}$, could promote the rupture of aromatics and the alkyl side chain of aliphatic hydrocarbon and volatilization of gaseous product. The schematic diagram of the combination of alkali metal and carbon is presented in Fig. 8. Generally, aromatic hydrocarbons hardly reacted with oxygen ions or hydroxyl ions. When the alkali metal exists in the char, it may react with the carbon atom on the edge of aromatic rings and form the $\mathrm{O}^{-} \mathrm{K}^{+}$ group. Due to the strong electron-withdrawing property of the $\mathrm{O}^{-} \mathrm{K}^{+}$group, the electron cloud of 1-carbon atom on the edge would move toward the $\mathrm{O}^{-} \mathrm{K}^{+}$group, leading to the 2 and 3-carbon atom losing electron partially. ${ }^{39)}$ As a consequence of a positive charge of the 2 and 3-carbon atom, the positively charged carbon atom was easier to combine with the negatively charged oxygen atom. Therefore, the combustion characteristic of the bamboo char was enhanced by the alkali metal.

Fourier transform infrared spectroscopy is one technique that could be used to investigate the functional groups change. The FTIR spectra of samples was recorded and the results are shown in Fig. 9. The $-\mathrm{OH}$ groups assigned to stretching vibration were at the $3600 \mathrm{~cm}^{-1}$ to $3000 \mathrm{~cm}^{-1}$ zone. Aromatic $\mathrm{C}-\mathrm{H}$ groups for bamboo char caused by out-of-plane bending vibration were at the $950 \mathrm{~cm}^{-1}$ to 620 $\mathrm{cm}^{-1}$ zone, which substantially decreased or even vanished 


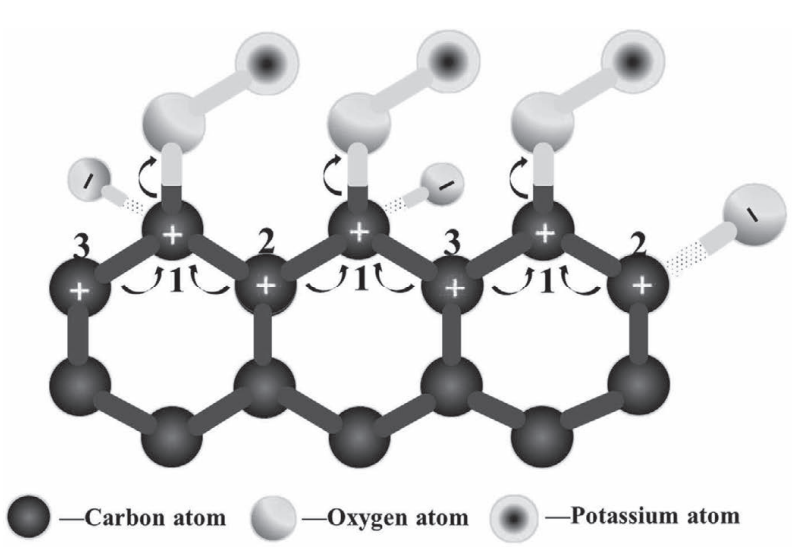

Fig. 8. Schematic diagram of the combination of alkali metal and carbon.

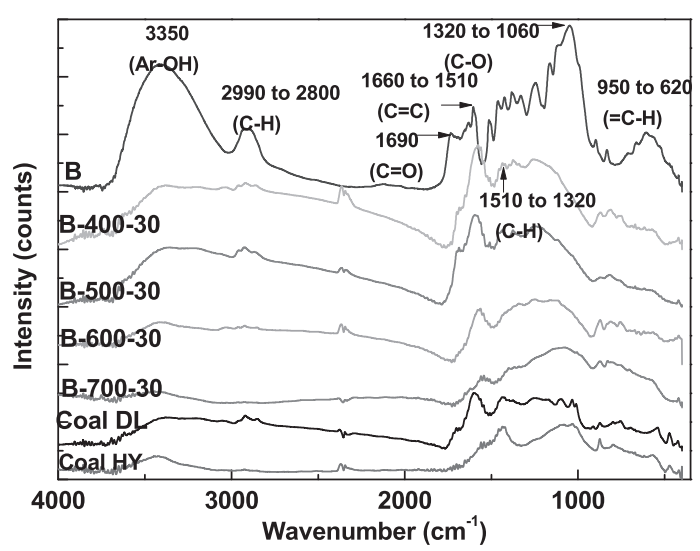

Fig. 9. FTIR analysis of bamboo char from different pyrolysis temperatures.

at the temperature of $400^{\circ} \mathrm{C} .{ }^{40)}$ At the temperature of above $500^{\circ} \mathrm{C}$, the intensity of the $-\mathrm{OH}$ bands for bamboo char around $3350 \mathrm{~cm}^{-1}$ disappeared entirely due to the decomposition of hemicellulose, even less than that of Coal HY. These results were consistent with reported literature. ${ }^{41)}$ Solely from the aspect of absorption intensity, although the FTIR spectra of Coal DL was apparently similar to that of B-600-30, and the FTIR spectra of Coal HY was similar to that of B-700-30, the combustion characteristic of all samples presented large differences.

It was found that coals with higher metamorphic grade had much more aromatic carbons, meaning the degree of carbon structure order is greater and has a good combustibility of samples. ${ }^{42}$ To quantitatively evaluate the effect of functional groups on the combustion characteristic, sample B-400-30 was taken as an example for the curve fitting. As shown in Fig. 10, the peak assignments followed the previous work. ${ }^{43}$ The relationship between the apparent aromaticity determined from FTIR spectrum and comprehensive combustion characteristic index $\mathrm{S}$ was shown in Fig. 11. The figure indicated that the apparent aromaticity $f_{\mathrm{a}(\mathrm{FTIR})}$ well corresponded to index $\mathrm{S}$ and the apparent aromaticity $f_{\mathrm{a}(\mathrm{FTIR})}$ of bamboo char increased with rising carbonization temperature as well. For the reason, FTIR could be used as a valuable method to synthesize the combined effects of carbonization temperature and duration on the property and structure of bamboo char.

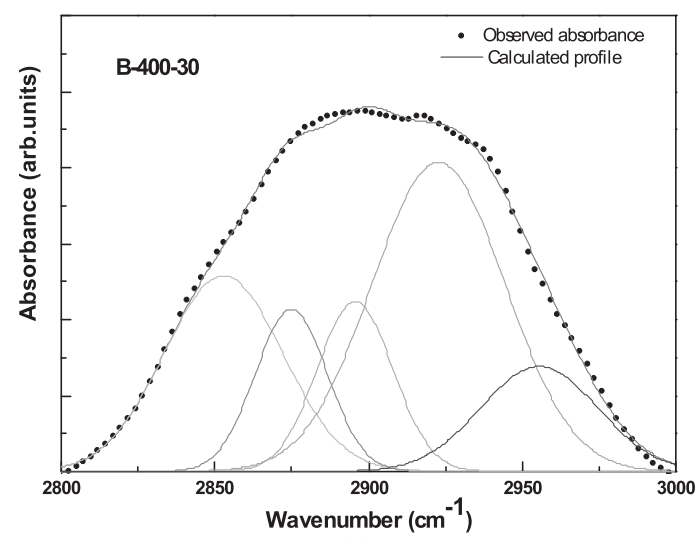

(a)

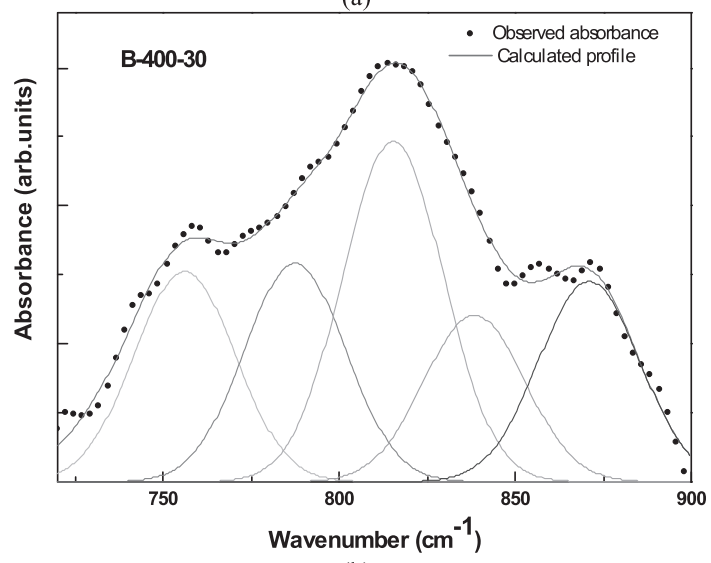

(b)

Fig. 10. Curve-fitting FTIR spectrum of sample B-400-30. (a): absorbance bands of aliphatic structures (b): absorbance bands of aromatic structures.

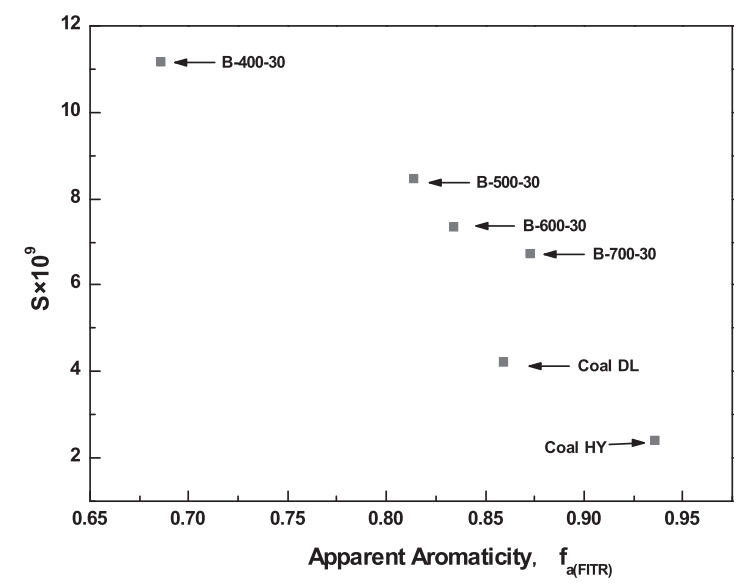

Fig. 11. Relationship between apparent aromaticity and comprehensive combustion characteristic index $\mathrm{S}$.

\section{Conclusions}

A series of experimental approach has been conducted to study the basic properties of bamboo char for injection in the blast furnace. Some findings of this study are listed as follows:

(1) Due to the high reactivity of three main compositions of bamboo, especially hemicellulose, the ratio of mass loss is more than $60 \%$ at $300^{\circ} \mathrm{C}$ and the process of carbonization decomposes completely at below $500^{\circ} \mathrm{C}$.

(2) Comparing with the effect of duration time on 
the solid yield, the economical and feasible duration time should be controlled within $30 \mathrm{~min}$. The fuel ratio of bamboo char shows a remarkable linear correlation with the rising temperature and falls in between that of bitumite coal and anthracite coal.

(3) Bamboo underwent great change in terms of its energy yield and chemical component during carbonization process. A modified formula was developed to calculate the higher heating value of bamboo char obtained at carbonization temperature above $300^{\circ} \mathrm{C}$ more accurately. Meanwhile, because of the positive impact of functional groups, specific surface area as well as catalysis of alkali metal, the bamboo char showed a better combustion performance.

(4) The carbonization at $400^{\circ} \mathrm{C}$ and holding time of 30 min were a feasible operating condition for improving the property and decreasing the energy loss of bamboo. The carbonized bamboo could partially replace the coal, and provided a promising approach for the utilization of bamboo for BF injection.

\section{Acknowledgments}

This work was supported by the Yong Elite Scientists Sponsorship Program By CAST(2017QNRC001) and the Natural Science Foundation for Young Scientists of China (No. 51804026).

\section{REFERENCES}

1) T. Ariyama, R. Murai, J. Ishii and M. Sato: ISIJ Int., 45 (2005), 1371.

2) H. Aoki, H. Nogami, H. Tsuge, T. Miura and T. Furukawa: ISIJ Int., 33 (1993), 646

3) H. Nogami, H. Yamaoka and K. Takatani: ISIJ Int., 44 (2004), 2150.

4) T. F. Song, J. L. Zhang, G. W. Wang, H. Y. Wang, R. S. Xu and Q. H. Pang: ISIJ Int., 58 (2018), 253.

5) M. F. Li, C. Z. Chen, X. Li, Y. Shen, J. Bian and R. C. Sun: Fuel, 161 (2015), 193.

6) R. C. Gupta: Miner. Process. Extr. Metall. Rev., 24 (2003), 203.

7) J. S. Tumuluru, L. G. Tabil, Y. Song, K. L. Iroba and V. Meda: Biomass Bioenergy, 60 (2014), 58.

8) V. S. P. Bitra, A. R. Womac, N. Chevanan, P. I. Miu, C. Igathinathane, S. Sokhansanj and D. R. Smith: Powder Technol., 193 (2009), 32.

9) M. Phanphanich and S. Mani: Bioresour. Technol., 102 (2011), 1246.

10) T. F. Song, J. L. Zhang, G. W. Wang, H. Y. Wang and R. S. Xu: ISIJ Int., 58 (2018), 1218.

11) R. S. Xu, J. L. Zhang, G. W. Wang, H. B. Zuo, P. C. Zhang and J. G. Shao: Chem. Eng. Res. Des., 107 (2016), 34

12) Y. P. Huang and H. C. Hsu: Ferroelectrics, 434 (2012), 1.
13) T. Norgate, N. Haque, M. Somerville and S. Jahanshahi: ISIJ Int., 52 (2012), 1472.

14) S. Ueda, K. Watanabe, K. Yanagiya, R. Inoue and T. Ariyama: ISIJ Int., 49 (2009), 1505.

15) P. Rousset, C. Aguiar, N. Labbé and J. M. Commandré: Bioresour. Technol., 102 (2011), 8255.

16) W. H. Chen, S. W. Du, C. H. Tsai and Z. Y. Wang: Bioresour. Technol., 111 (2012), 433.

17) M. F. Li, X. Li, J. Bian, J. K. Xu, S. Yang and R. C. Sun: Ind. Crop. Prod., 76 (2015), 149.

18) T. G. Bridgeman, J. M. Jones, I. Shield and P. T. Williams: Fuel, 87 (2008), 844.

19) M. Dudyński, J. C. V. Dyk, K. Kwiatkowski and M. Sosnowska: Fuel Process. Technol., 131 (2015), 203.

20) S. W. Du, W. H. Chen and J. A. Lucas: Bioresour. Technol., 161 (2014), 333.

21) H. Y. Li, L. Elliott, H. Rogers and T. Wall: Energy Fuels, 28 (2014), 363.

22) R. H. Essenhigh, M. K. Misra and D. W. Shaw: Combust. Flame, 77 (1989), 3.

23) J. Cheng, J. Zhou and J. Liu: J. Fuel Chem. Technol., 67 (2004), 297.

24) P. R. Solomon and R. M. Carangelo: Fuel, 67 (1988), 949.

$25)$ P. R. Solomon and R. M. Carangelo: Fuel, 61 (1982), 663.

26) J. Parikh, S. Channiwalab and G. Ghosalc: Fuel, 84 (2005), 487.

27) P. Williams and S. Besle: Renew. Energy, 7 (1996), 233.

28) A. V. Maciel, A. E. Job, W. D. N. Mussel, W. D. Brito and V. M. D. Pasa: Biomass Bioenergy, 35 (2011), 1121.

29) F. Liang, R. J. Wang, X. H. Zhong, X. M. Yang, T. Zhang, W. H. Hu, B. B. Mi and Z. J. Liu: Bioresour. Technol., 256 (2018), 53.

30) M. Li, X. Li, J. Bian, C. Chen, Y. Yu and R. Sun: Biomass Bioenergy, 83 (2015), 366.

31) K. I. Ohno, A. Babich, J. Mitsue, T. Maeda, D. Senk, H. W. Gudenau and M. Shimizu: ISIJ Int., 52 (2012), 1482.

32) A. K. Majumder, R. Jain, P. Banerjee and J. P. Barnwal: Fuel, 87 (2008), 3077.

33) W. Chen and P. Kuo: Energy, 35 (2010), 2580.

34) Z. Liu, B. Fei, Z. Jiang and X. Liu: Bioresour. Technol., 167 (2014), 94.

35) A. Demirbas, D. Gullu, A. Caglar and F. Akdeniz: Energy Sources, 19 (1997), 765.

36) A. Aho, N. Kumar, K. Eränen, B. Holmbom, M. Hupa, T. Salmi and D. Y. Murzin: Int. J. Mol. Sci., 9 (2008), 1665.

37) G. Almeida, J. O. Brito and P. Perré: Bioresour. Technol., 101 (2010), 9778.

38) B. S. Chiou, D. V. Valenzuela-Medina, C. B. Bilbao-Sainz, A. K. Klamczynski, R. J. A. Avena-Bustillos, R. R. Milczarek, W. X. Du, G. M. Glenn and W. J. Orts: Bioresour. Technol., 177 (2015), 58.

39) G. W. Wang, J. L. Zhang, J. G. Shao, Z. J. Liu, G. H. Zhang, T. Xu, J. Guo, H. Y. Wang, R. S. Xu and H. Lin: Energy Convers. Manag., 124 (2016), 414.

40) E. L. Zodrow, M. Mastalerz, U. Werner-Zwanziger and J. A. D’Angelo: Int. J. Coal Geol., 82 (2010), 116.

41) Y. Wang, J. Zhou, L. Bai, Y. Chen, S. Zhang and X. Lin: Energy Fuels, 28 (2014), No. 2, 862.

42) S. G. Chen and R. T. Yang: Energy Fuels, 11 (1997), 421.

$43)$ P. C. Painter, R. W. Snyder, M. Starsinic, M. M. Coleman, D. W. Kuehn and A. Davis: Appl. Spectrosc., 35 (1981), 475. 